\title{
IMPLEMENTASI FORMULA HAVERSINE DAN KOMUNIKASI DATA REAL-TIME MENGGUNAKAN WEBSOCKET DI SISTEM PENGAWASAN WARGA NEGARA ASING
}

\author{
Rianto $^{1}$, Febryanata ${ }^{2}$, Alam Rahmatulloh ${ }^{3}$ \\ Jurusan Teknik Informatika, Universitas Siliwangi \\ Jalan Siliwangi No. 24 Kota Tasikmalaya \\ rianto@unsil.ac.id ${ }^{1}$, febryanata4@student.unsil.ac.id², alam@unsil.ac.id ${ }^{3}$
}

\begin{abstract}
Foreign Citizens (FC) after entering Indonesian territory according to applicable legal procedures, the presence of foreigners can be anywhere. Problems also arise when parties involved in supervising foreigners cannot contact foreigners who experience immigration problems and do not know the location of the presence of current foreigners or where they were. One solution to this problem is implementing real time data communication to monitor the location of foreigners, so that foreigners can always be monitored. Before going to the residence, a consideration is needed to determine which residence of the foreigner to be visited. Knowing the distance of a foreigner's residence can be an added point in these considerations. The Haversine method is implemented by calculating the distance between parties involved in the supervision of foreigners with each address of the foreigner's residence. The comparison test results of the Haversine method with Google Maps in this study, which has an average difference of $0.039 \mathrm{~km}$ in terms of distance based on a straight line. Real time data communication technology using websocket is implemented into a WNA surveillance system, consisting of web-based applications and android-based applications that are interconnected into websocket networks. The average results of profiling the speed of writing data for 15 minutes from the smartphone to the real time firebase database which is 1.4 milliseconds with 10 seconds of data transmission interval from the smartphone and the results of the average speed of receiving data from firebase realtime database to the WNA monitoring system ie 0 , 36 seconds with the data receiving interval from firebase realtime database 10 seconds.
\end{abstract}

Keywords: Firebase Realtime Database, Foreign Citizens, Haversine, Websocket

\begin{abstract}
Abstrak
Warga Negara Asing (WNA) setelah memasuki wilayah Indonesia sesuai prosedur hukum yang berlaku, maka keberadaan WNA dapat berada dimana saja. Masalah pun timbul ketika pihak yang terlibat dalam pengawasan WNA tidak dapat menghubungi WNA yang mengalami masalah keimigrasian dan tidak mengetahui lokasi keberadaan WNA saat ini ataupun lokasi keberadaan sebelumnya. Salah satu solusi dari permasalahan tersebut yaitu mengimplementasikan komunikasi data real time untuk mengawasi lokasi keberadaan WNA, sehingga pergerakan WNA dapat selalu terawasi. Sebelum mendatangi tempat tinggal tersebut, dibutuhkan sebuah pertimbangan untuk menentukan tempat tinggal WNA mana dulu yang akan didatangi. Mengetahui jarak tempat tinggal WNA dapat menjadi poin tambah dalam pertimbangan tersebut. Metode haversine diimplementasikan dengan cara menghitung jarak antara pihak yang terlibat dalam pengawasan WNA dengan setiap alamat
\end{abstract}

Haversine Dan Komunikasi Data Real-Time Websocket Di Sistem Pengawasan WNA (Alam R)|143 
tempat tinggal WNA. Hasil pengujian perbandingan metode haversine dengan google maps pada penelitian ini yaitu mempunyai rata-rata selisih sebesar 0,039 $\mathrm{km}$ dalam hal jarak berdasarkan garis lurus. Teknologi komunikasi data real time menggunakan websocket diimplementasikan kedalam sebuah sistem pengawasan WNA, terdiri dari aplikasi berbasis web dan aplikasi berbasis android yang saling terhubung kedalam jaringan websocket. Hasil rata-rata profiling kecepatan proses tulis data selama 15 menit dari smartphone ke firebase realtime database yaitu 1,4 milidetik dengan interval pengiriman data dari smartphone 10 detik sekali dan hasil rata-rata kecepatan penerimaan data dari firebase realtime database ke sistem pengawasan WNA yaitu 0,36 detik dengan interval penerimaan data dari firebase realtime database 10 detik sekali.

Kata kunci: Firebase Realtime Database, Haversine, Pengawasan WNA, Websocket

\section{PENDAHULUAN}

Dampak globalisasi dunia menyebabkan lalu lintas orang antar bangsa meningkat, sehingga batas-batas negara semakin mudah dilalui. Hal tersebut menjadi perhatian disetiap negara khususnya Indonesia. Terlebih lagi dengan adanya kebijakan bebas visa kunjungan yang diatur dalam Peraturan Presiden Nomor 21 Tahun 2016 tingkat populasi Warga Negara Asing (WNA) yang datang ke Indonesia dapat semakin meningkat. Tercatat sebanyak 254 data WNA yang masih aktif hingga tanggal 30 April 2018 pada wilayah Priangan Timur [1].

Pengawasan dilakukan berdasarkan UU Nomor 6 Tahun 2011 Pasal 68 yang menyatakan bahwa pengawasan keimigrasian terhadap WNA dilaksanakan pada saat permohonan visa, masuk atau keluar, dan pemberian izin tinggal serta pengawasan terhadap keberadaan dan kegiatan WNA di wilayah Indonesia [2].

Ketika WNA telah memasuki wilayah Indonesia sesuai prosedur hukum yang berlaku, maka keberadaan WNA dapat berada dimana saja. Masalah pun timbul ketika pihak yang terlibat dalam pengawasan WNA tidak dapat menghubungi WNA yang mengalami masalah keimigrasian dan tidak mengetahui lokasi keberadaan WNA saat ini ataupun lokasi keberadaan sebelumnya. Salah satu solusi dari permasalahan tersebut yaitu mengimplementasikan komunikasi data real time untuk mengawasi lokasi keberadaan WNA, sehingga pergerakan WNA dapat selalu terawasi. Beberapa teknologi yang dapat menyajikan informasi secara real time pada aplikasi berbasis web diantaranya yaitu Asynchronous JavaScript and XML (AJAX) dan websocket, tetapi AJAX memiliki kekurangan dalam meningkatkan performa sistem dibandingkan websocket [3], sedangkan websocket merupakan teknologi yang dianggap akan banyak digunakan dalam penyajian data real-time menggantikan AJAX [4], [5], [6]. Websocket mempunyai nilai Round Trip Time (RTT) lebih baik dibandingkan dengan AJAX [7]. Ukuran HTTP Headers dari proses request-response yang dihasilkan websocket lebih kecil daripada metode komunikasi data secara real time seperti HTTP Polling dan HTTP Long Poling [8].

Pihak yang terlibat dalam pengawasan WNA juga berwenang mendatangi tempat-tempat yang diduga dapat ditemukan bahan keterangan mengenai keberadaan WNA dan kegiatannya [9] salah satunya yaitu tempat tinggal. Sebelum mendatangi tempat tinggal tersebut, dibutuhkan sebuah pertimbangan untuk menentukan tempat tinggal WNA mana dulu yang akan didatangi. Mengetahui jarak

Haversine Dan Komunikasi Data Real-Time Websocket Di Sistem Pengawasan WNA (Alam R)|144 
tempat tinggal WNA dapat menjadi nilai tambah dalam pertimbangan tersebut. Untuk mengetahui jarak tempat tinggal tersebut, dibutuhkan metode perhitungan jarak [10]. Terdapat beberapa metode perhitungan jarak antara dua lokasi yang dapat digunakan, diantaranya yaitu metode euclidean distance dan metode haversine. Metode haversine adalah perhitungan antara dua titik pada permukaan bola (bumi) berdasarkan bujur dan lintang [11]. Perbandingan perhitungan metode haversine dengan metode euclidean distance yaitu perhitungan euclidean distance dengan ukuran dua dimensi akan gagal jika melakukan perhitungan jarak antara dua lokasi yang salah satu lokasinya sangat jauh hingga keluar batas wilayah seperti berbeda pulau, karena tidak memperhitungkan kelengkungan bumi [12].

Berdasarkan uraian yang telah disampaikan, maka tujuan penelitian ini yaitu menentukan siapa dulu WNA yang akan didatangi berdasarkan jarak tempat tinggal WNA dan menerapkan teknologi komunikasi data real time untuk pengawasan keberadaan WNA dengan memanfaatkan firebase realtime database [13].

\section{METODOLOGI PENELITIAN}

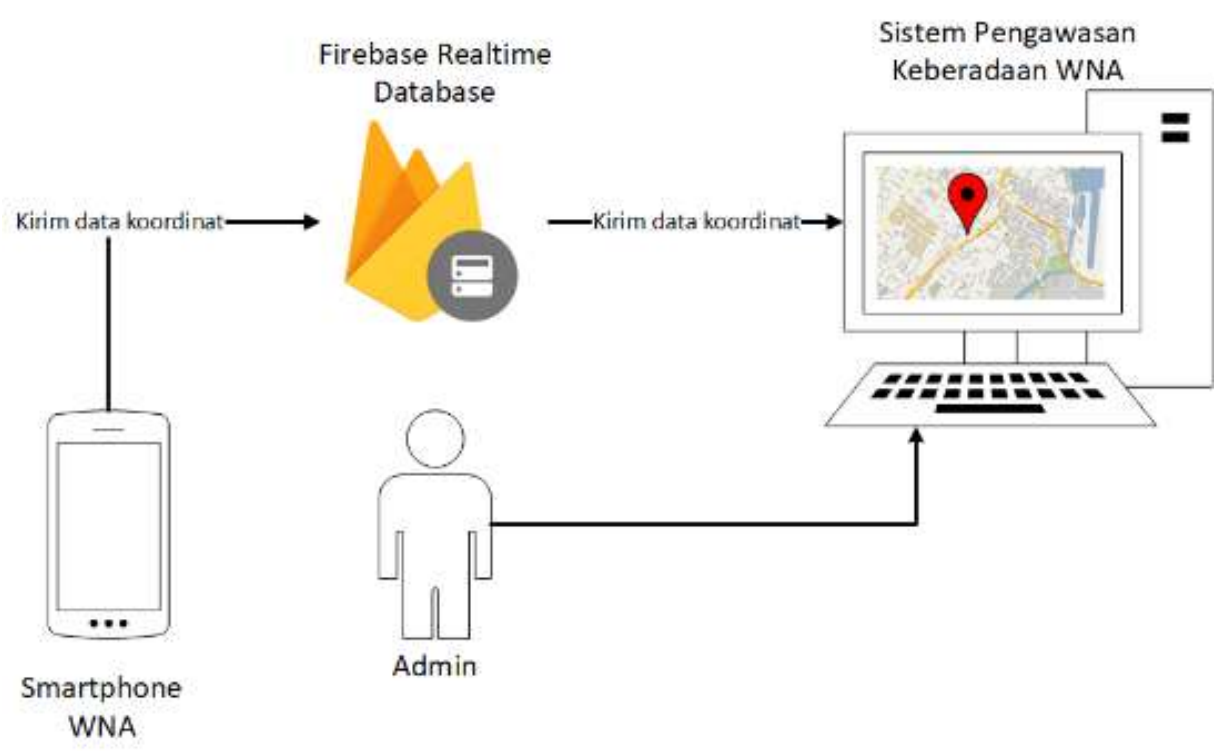

Gambar 1. Arsitektur Sistem

Gambar 1 merupakan gambar arsitektur sistem pengawasan keberaadan WNA. Smartphone WNA mengirim data koordinat lokasi yang didapat dari GPS kemudian data koordinat tersebut dikirimkan ke firebase realtime database, kemudian dari firebase realtime database diteruskan kembali ke Sistem Pengawasan WNA. Sistem tersebut memiliki peta dan marker sebagai penanda posisi dari koordinat yang diterima dari firebase realtime database tersebut. Marker tersebut akan bergerak dengan sendirinya berdasarkan data koordinat yang diterima.

a. Perencanaan (Planning)

1) Identifikasi Permasalahan

WNA yang berada di Indonesia harus selalu diawasi sehingga pihak yang terlibat dalam hal pengawasan WNA (lembaga keimigrasian, dan lain-lain), dapat mengambil tindakan jika WNA tersebut mengalami masalah keimigrasian. Pengawasan WNA membutuhkan teknologi real time sehingga 
data keberadaan yang didapat selalu terkini setiap kali terdapat perubahan. Permasalahan ini salah satunya dialami oleh Kantor Imigrasi Kelas II Tasikmalaya, yang saat ini belum memiliki sebuah sistem pengawasan untuk keberadaan WNA yang dapat memetakan alamat WNA secara digital dan real time.

2) Analisis Kebutuhan Data, dapat dilihat pada tabel I.

Tabel I. Analisis Kebutuhan Data

\begin{tabular}{cl}
\hline \multicolumn{1}{c}{ Nama Data } & \multicolumn{1}{c}{ Atribut } \\
\hline Data WNA & Nama, Kewarganegaraan, Jenis Kelamin, No \\
& Paspor, Masa Berlaku Paspor, Tempat Lahir, \\
& Tanggal Lahir, Alamat di Indonesia, Email, \\
& No. Kontak, Nama Sponsor, dan Alamat \\
& Sponsor \\
Data Izin Tinggal & NIORA, No. Izin Tinggal, Jenis Izin Tinggal, \\
& Masa Berlaku Izin Tinggal dan Status Izin \\
& Tinggal \\
\hline
\end{tabular}

3) Analisis Kebutuhan Fungsional

Kebutuhan fungsional sistem pengawasan WNA yaitu sistem dapat menginputkan data WNA, sistem dapat menampiilkan alamat tempat tinggal WNA dalam bentuk peta, sistem dapat mengawasi keberadaan WNA secara realtime dalamm bentuk peta, sistem dapat memberi informasi tentang masa berlaku izin tinggal yang dimiliki WNA.

4) Analisis Kebutuhan Non Fungsional

Kebutuhan non fungsional sistem pengawasan keberadan WNA yaitu membutuhkan PC yang terhubung dengan jaringan internet, membutuhkan web browser terbaru serta tersedia web server, PHP 7 dan MySQL.

b. Perancangan (Design)

1) Identifikasi Pengguna, terdapat 2 pengguna pada sistem pengawasan WNA yaitu Seksi Pengawasan dan Penindakan Keimigrasian (Wasdakim) sebagai Admin dan WNA.

2) Identifikasi Use Case, dapat dilihat pada gambar 2.

3) Skenario Use Case, merupakan alur jalannya proses use case dari mulai sisi aktor dan sisi sistem.

4) Class Diagram, merupakan gambaran model statis yang menggambarkan struktur dan deskripsi serta hubungan antar class, dapat dilihat pada gambar 3.

5) Activity Diagram, dibuat untuk menjelaskan aktivitas komputer maupun alur aktivitas dalam organisasi. 


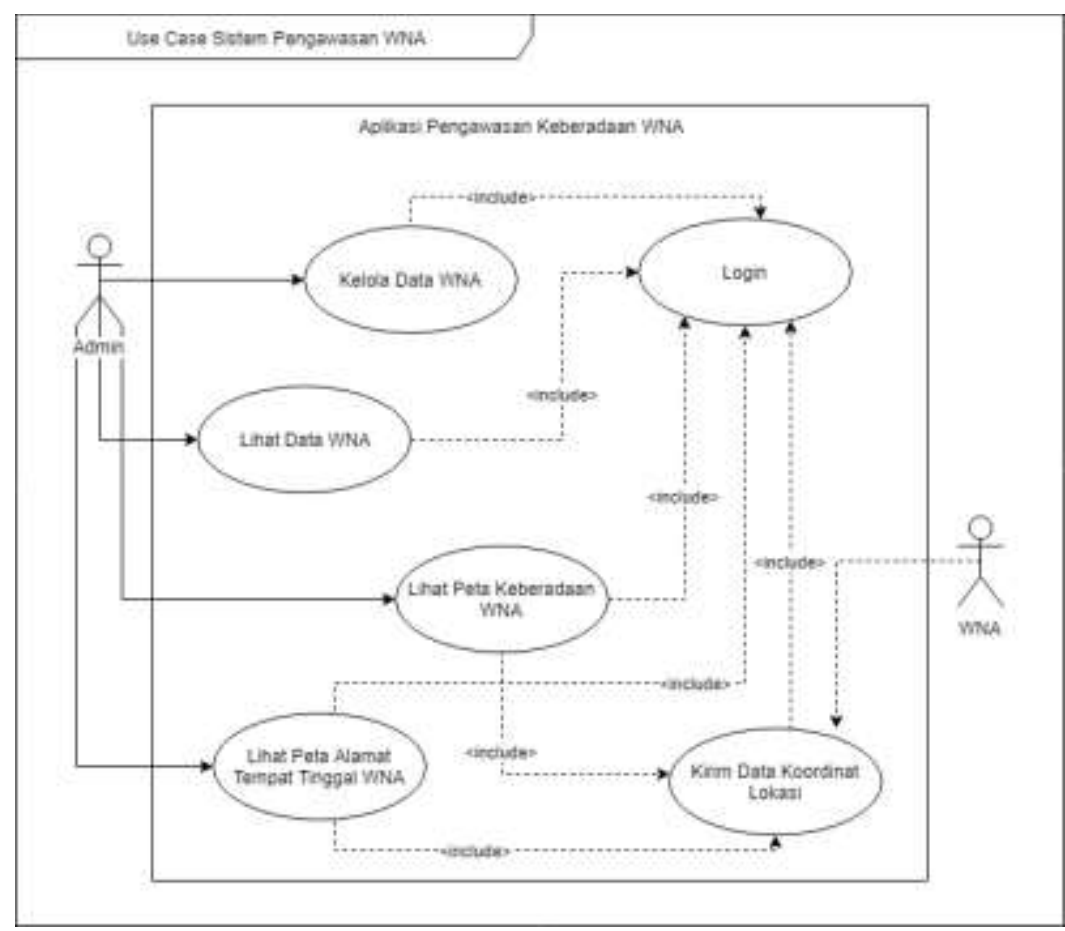

Gambar 2. Use Case

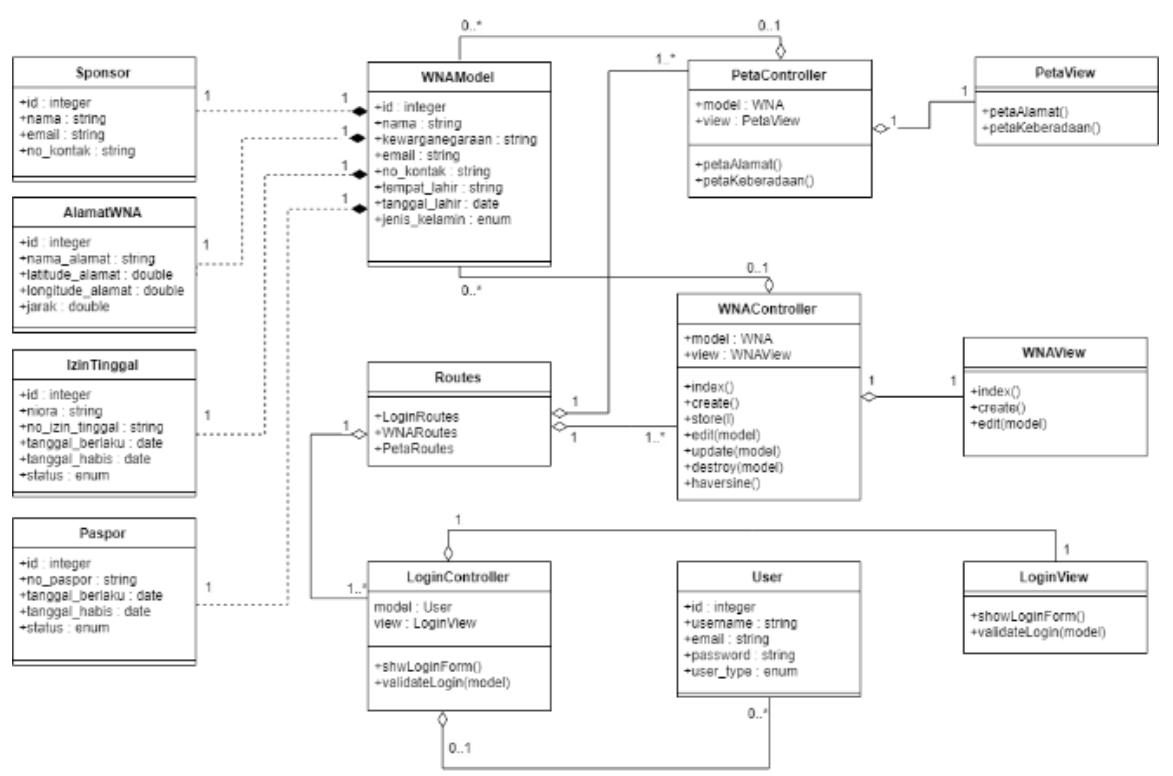

Gambar 3. Class Diagram

\section{HASIL DAN PEMBAHASAN}

\subsection{Implementasi Sistem}

Hasil implementasi sistem dapat dilihat pada gambar 4a dan 4b. Gambar 4 merupakan tampilan halaman peta alamat tempat tinggal WNA. Halaman ini menampilkan data WNA terkait alamat tempat tinggal, izin tinggal dan jarak antara Kantor Imigrasi Kelas II Tasikmalaya menuju alamat tempat tinggal WNA. 


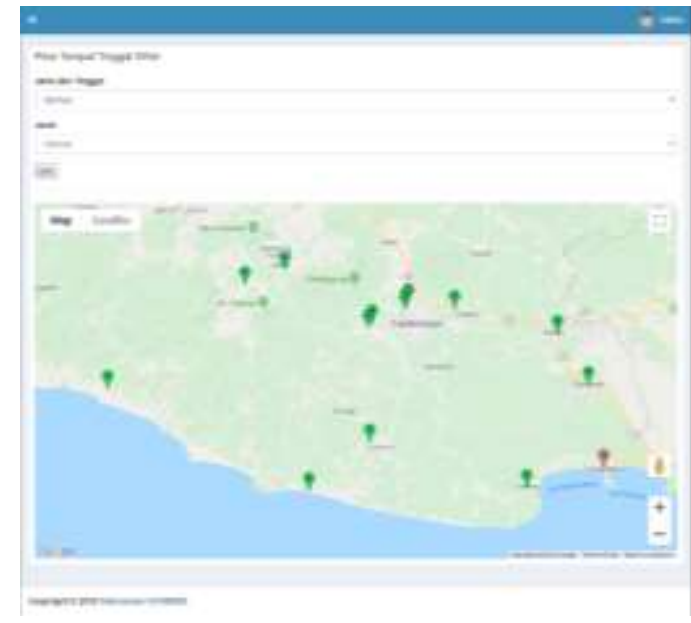

(a)

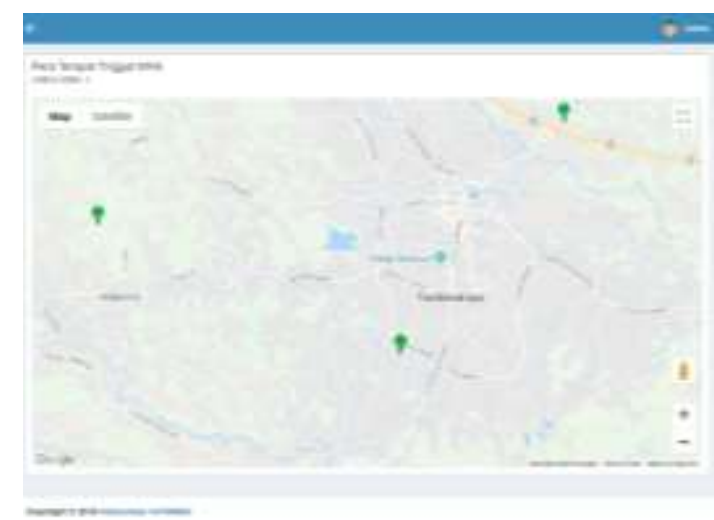

(b)

Gambar 4. Halaman Peta Keberadaan WNA

\subsection{Pengujian (Testing)}

\subsubsection{Pengujian Black Box}

Hasil pengujian black box terhadap sistem pengawasan keberadaan WNA mendapatkan kesimpulan berhasil sesuai harapan pada setiap pengujian yang dilakukan.

\subsubsection{Pengujian Realtime Database}

\begin{tabular}{|c|c|c|}
\hline Data & Length & Time \\
\hline I\{"t":"c","d":\{"t":"h","d"\{:ts":1542170427950,"v":"5","h":"s-usc... & 132 & $11: 40: 27.251$ \\
\hline t\{"t":"d","d":\{"r":1,"a":"s","b":\{"c":\{"sdk.js.5-5-5":1\}\}\}\} & 58 & $11: 40: 27.257$ \\
\hline t\{"t":"d","d":\{"r":2,"a":"q","b":\{"p":"/locations","h":"" \}\}\} & 59 & $11: 40: 27.258$ \\
\hline I\{"t":"d","d":\{"r":1,"b":\{"s":"ok","d":""]\}\} & 43 & $11: 40: 27,495$ \\
\hline I\{"t":"d","d":\{"b":["p":"locations","d":\{"1":\{"accuracy":7.585000... & 1425 & $11: 40: 27.496$ \\
\hline I\{"t":"d","d":\{"r":2,"b":\{"s":"ok","d":\{\}\}\}\} & 43 & $11: 40: 27.542$ \\
\hline I\{"t":"d","d":\{"b":\{"p":"locations/11","d":\{"accuracy":20.202999... & 364 & $11: 40: 37.136$ \\
\hline I\{"t":"d","d":\{"b":\{"p":"locations/11","d":\{"accuracy":19.295999... & 364 & $11: 40: 47.918$ \\
\hline I\{"t":"d","d":\{"b":\{"p":"locations/11","d":\{"accuracy":18.742000... & 365 & $11: 40: 58.266$ \\
\hline I\{"t":"d","d":\{"b":\{"p":"locations/11","d":\{"accuracy":18.961000... & 364 & $11: 41: 08.131$ \\
\hline I\{"t":"d","d":\{"b":\{"p":"locations/11","d":\{"accuracy":18.188999... & 364 & $11: 41: 18.187$ \\
\hline I\{"t":"d","d":\{"b":["p":"locations/11","d":\{"accuracy":17.702999... & 365 & $11: 41: 29.251$ \\
\hline I\{"t":"d","d":\{"b":\{"p":"locations/11","d":\{"accuracy":17.382999... & 365 & $11: 41: 39.272$ \\
\hline I\{"t":"d","d":\{"b":\{"p":"locations/11","d":\{"accuracy":16.996999... & 366 & $11: 41: 49.292$ \\
\hline I\{"t":"d","d":\{"b":\{"p":"locations/11","d":\{"accuracy":17.277999... & 363 & $11: 42: 00.384$ \\
\hline I\{"t":"d","d":\{"b":\{"p":"locations/11","d":;"accuracy":16.870000... & 363 & $11: 42: 11.834$ \\
\hline I\{"t":"d","d":\{"b":\{"p":"locations/11","d":\{"accuracy":16.812000... & 365 & $11: 42: 20.973$ \\
\hline I\{"t":"d","d":\{"b":\{"p":"locations/11","d":\{"accuracy":16.780000... & 365 & $11: 42: 31.357$ \\
\hline I\{"t":"d","d":\{"b":["p":"locations/11","d":\{"accuracy":16.757999... & 366 & $11: 42: 41.389$ \\
\hline I\{"t":"d","d":\{"b":\{"p":"locations/11","d":\{"accuracy":16.75,"altit... & 351 & $11: 42: 51,472$ \\
\hline
\end{tabular}

\section{Gambar 5 Proses Pertukaran Data}

Gambar 5 menunjukan kecepatan membaca data firebase database realtime pada sistem pengawasan WNA yaitu 0-12 ms.

\subsubsection{Pengujian Perbandingan Hasil Metode Havesine}

Pengujian ini dilakukan dengan cara mengurutkan hasil perhitungan metode haversine oleh sistem dari yang terkecil hingga terbesar kemudian membandingkan hasil perhitungan jarak tersebut dengan hasil google maps berdasarkan garis lurus. 
Data yang dijadikan sampel sebanyak 10 data. Hasil pengujian perbandingan hasil metode haversine dapat dilihat pada tabel 2.

Tabel 2 Hasil Pengujian Perbandingan

\begin{tabular}{clcc}
\hline \multirow{2}{*}{ No } & \multicolumn{1}{c}{ Alamat } & \multicolumn{2}{c}{ Jarak (km) } \\
\cline { 3 - 4 } & & $\begin{array}{c}\text { Sistem } \\
\text { (Garis } \\
\text { Lurus) }\end{array}$ & $\begin{array}{c}\text { Google Maps } \\
\text { (Garis } \\
\text { Lurus) }\end{array}$ \\
\hline 1 & Jalan Cijolang No 30 Tasikmalaya & 0,65 & 0,61 \\
2 & Jalan Cimuncang No 21 Tasikmalaya & 1,79 & 1,67 \\
3 & Jalan Rancabango No 30 Tasikmalaya & 1,91 & 1,96 \\
4 & Jalan Pancawarna No 40 Singaparna & 10,16 & 10,36 \\
5 & Jalan Raya Mangunreja No 20 & 11,73 & 11,93 \\
6 & Tasikmalaya & 12,45 & 12,21 \\
7 & Jalan Raya Garut Cikajang & 32,18 & 32,41 \\
8 & Jalan Jadimulya No 5 Banjar & 39,56 & 39,32 \\
9 & Jalan Pasundan No 4 Cijulang & 56,49 & 56,36 \\
10 & Jalan Merdeka No 20 Pangandaran & 65,82 & 65,63 \\
\hline
\end{tabular}

Hasil pengujian perbandingan yaitu selisih rata-rata nilai jarak yang dihasilkan sistem tidak jauh berbeda yaitu 0,039 km jika dibandingkan dengan google maps dalam hal jarak berdasarkan garis lurus.

\subsection{Profiling Firebase Realtime Database}

Profiling menggunakan database profile milik Firebase, menggunakan koneksi internet 4G, dan dilakukan di dalam ruangan. Kegunaan profiling pada penelitian ini yaitu untuk mengetahui performa kecepatan dari firebase realtime database yang digunakan oleh sistem pengawasan WNA. Profiling dilakukan dengan cara mengamati operasi baca dan tulis yang terjadi selama 15 menit.

Hasil profiling tersebut yaitu kecepatan proses baca dan tulis yang terjadi pada firebase realtime database yang digunakan oleh sistem pengawasan WNA masih dalam satuan milidetik, yaitu 0 milidetik dan 1,41 milidetik dengan interval pengiriman data dari smartphone 10 detik sekali. Tetapi hasil rata-rata kecepatan tersebut tidak mencerminkan kecepatan aktual pada sisi pengguna akhir, karena banyak faktor yang mempengaruhi, termasuk kondisi jaringan dapat menambah latensi pada sisi klien.

\section{SIMPULAN}

Berdasarkan hasil penelitian yang telah dilakukan, dapat disimpulkan sebagai berikut:

a. Penerapan metode haversine telah berhasil pada sistem pengawasan WNA, namun berdasarkan hasil pengujian metode ini kurang cocok karena faktanya untuk mengunjungi tempat tinggal WNA tidak bisa hanya dengan menempuh 
perjalanan berdasarkan garis lurus saja tetapi terdapat rute jalan ke setiap tempat tinggal WNA.

b. Teknologi komunikasi data real time diterapkan kedalam sebuah sistem pengawasan WNA, terdiri dari aplikasi berbasis web dan aplikasi berbasis android yang saling terhubung kedalam jaringan websocket. Aplikasi berbasis $w e b$ dapat menampilkan dan menyimpan data lokasi yang dikirim dari aplikasi berbasis android. Sehingga data lokasi keberadaan WNA tersimpan secara terus menerus kemudian dapat digunakan untuk mengetahui riwayat lokasi WNA. Hal tersebut membuat pihak yang terlibat dalam pengawasan WNA dapat melihat keberadaan terakhir maupun keberadaan selama aplikasi berbasis android terus mengirimkan data lokasi. Hasil rata-rata profiling kecepatan proses tulis data selama 15 menit dari smartphone ke firebase realtime database yaitu 1,4 milidetik dengan interval pengiriman data dari smartphone 10 detik sekali dan hasil rata-rata kecepatan penerimaan data dari firebase realtime database ke sistem pengawasan WNA yaitu 0,36 detik dengan interval penerimaan data dari firebase realtime database 10 detik sekali.

\section{DAFTAR PUSTAKA}

[1] Imigrasi, "Kantor Imigrasi Kelas II Tasikmalaya." [Online]. Available: http://imigrasitasikmalaya.com.

[2] M. Arif and Rubiana, "Sistem Informasi Pengumpulan Data Statistik Lalu Lintas WNA dan WNI Pada Kantor BPS Kabupaten Kepulauan Meranti," in Seminar Nasional dan Kongres IndoMS Wilayah Sumatera Bagian Tengah FMIPA Universitas Riau, 2014.

[3] A. R. Maulana and A. Rahmatulloh, "Websocket untuk Optimasi Kecepatan Data Transfer pada Real Time Chatting," Innov. Res. Informatics, vol. 1, no. 1, pp. 7-12, 2019.

[4] Q. Liu and X. Sun, "Research of Web Real-Time Communication Based on Web Socket," Int. J. Commun. Netw. Syst. Sci., 2012.

[5] V. Wang, F. Salim, P. Moskovits, V. Wang, F. Salim, and P. Moskovits, "The WebSocket Protocol," in The Definitive Guide to HTML5 WebSocket, 2013.

[6] I. Fette and A. Melnikov, "RFC 6455 - The WebSocket Protocol," Internet Eng. Task Force, 2011.

[7] H. Husen, A. Rahmatulloh, and H. Sulastri, "Implementasi Komunikasi Full Duplex Menggunakan Web Socket Pada Sistem Informasi Pengelolaan Anggaran Universitas Abc," Simetris J. Tek. Mesin, Elektro dan Ilmu Komput., vol. 9, no. 1, pp. 603-612, 2019.

[8] S. M. Rakhunde, "Real Time Data Communication over Full Duplex Network Using Websocket," IOSR J. Comput. Sci., 2014.

[9] Muharmonth and R. A. Andi M, "Prosedur Pengawasan Keimigrasian Terhadap Warga Negara Asing Yang Diberikan Fasilitas Bebas Visa Kunjungan Wisata Kantor Imigrasi Kelas I Padang," JOM FISIP, 2017.

[10] R. A. Fauji, A. Rahmatulloh, and A. P. Aldya, "Implementation Of Global Positioning System As A Location Monitoring Media For Final Project Guidelines On Android- Based Applications," vol. 16, no. 2, pp. 169-174, 2019. 
[11] N. S. Ryan Herwan Dwi Putra, Herry Sujiani, "Penerapan Metode Haversine Formula Pada Sistem Informasi Geografis Pengukuran Luas Tanah," J. Sist. dan Teknol. Inf., 2016.

[12] F. Ivis, "Calculating geographic distance: Concepts and methods," Proc. 19th Annu. Northeast SAS Users Gr., 2006.

[13] L. Moroney and L. Moroney, "The Firebase Realtime Database," in The Definitive Guide to Firebase, 2017. 